\title{
Planos de Nutrição para Frangos de Corte no Período de 1 a 49 Dias de Idade Mantidos em Condições de Conforto Térmico
}

\author{
Paulo Segatto Cella ${ }^{2}$, Juarez Lopes Donzele ${ }^{3}$, Rita Flávia Miranda de Oliveira ${ }^{3}$, Luiz Fernando \\ Teixeira Albino ${ }^{3}$, Aloísio Soares Ferreira ${ }^{3}$, Paulo Cezar Gomes ${ }^{3}$, Sandra Roselí Valerio ${ }^{4}$, \\ Lourdes Romão Apolônio 5
}

\begin{abstract}
RESUMO - Utilizaram-se 240 frangos de corte machos Ross, com peso inicial médio de $43 \pm 0,2$ g, no período de 1 a 49 dias de idade, mantidos em condições de conforto térmico $\left(24,2 \pm 3,52^{\circ} \mathrm{C}\right)$. O delineamento experimental foi o inteiramente casualizado com quatro planos de nutrição PN1 (1,10; 1,00; e $0,85 \%$ de lisina total), PN2 (1,20; 1,10; e $0,95 \%$ de lisina total), PN3 (1,30; 1,20 ; e 1,05\% de lisina total) e PN4 (1,40; 1,30; e 1,15\% de lisina total), respectivamente, para as fases de 1 a 21,22 a 41 e 42 a 49 dias de idade e seis repetições de dez aves até os 41 dias de idade e de sete aves dos 42 aos 49 dias de idade. Avaliou-se o efeito dos níveis de lisina sobre desempenho, peso e rendimento de cortes nobres e vísceras comestíveis. O ganho de peso, a conversão alimentar e o consumo de ração não foram influenciados pelos tratamentos, entretanto, os pesos, absoluto e relativo, de peito, peito sem osso e fígado foram influenciados. Com base nos resultados de desempenho, qualquer dos planos avaliados atende às exigências de frangos de corte nas diferentes fases estudadas, quando mantidos em ambiente de conforto térmico, e, se considerados os dados de rendimentos de cortes nobres, os planos 2, 3 e 4 proporcionaram os melhores resultados.
\end{abstract}

Palavras-chave: ambiente, aminoácido, cortes nobres, desempenho, lisina

\section{Nutrition Plans for Broilers at the Period from 1 to 49 Days of Age Maintained in Conditions of Thermal Comfort}

\begin{abstract}
Two hundred and forty male broilers of Ross strain, with initial weight of $43 \pm 0.2 \mathrm{~g}$, from 1 to 49 days of age, were maintained under thermal comfort $\left(24.2 \pm 3.52^{\circ} \mathrm{C}\right)$. A completely randomized design with four nutrition plans was used: NP1 (1.1, 1.0, and $0.85 \%$ de total lysine); NP2 (1.2, 1.1, and $0.95 \%$ de total lysine); NP3 (1.3, 1.2, and $1.05 \%$ of total lysine); and NP4 (1.4, 1.3 , and $1.15 \%$ de total lysine), respectively for the periods from 1 to 21 days, 22 to 41 days and 42 to 49 days of age, six replicates of ten birds until 41 days of age and of seven birds from 42 to 49 days of age. The effect of lysine level on performance, weight and yield of special cuts and edible viscera were evaluated. Weight gain, feed: gain ratio and feed intake were not influenced by treatments. However, the relative and absolute weight of breast, breast without bone and liver were influenced by treatments. Based on the performance results it was concluded that any nutrition plan met the requirements of broilers for all studied phases when they are kept under environment of thermal comfort. Considering the special cut yield values, the 2, 3 and 4 nutrition plans support the best results.
\end{abstract}

Key Words: environment, amino acid, noble cuts, performance, lysine

\section{Introdução}

A produtividade animal ótima é obtida quando os animais são mantidos em ambiente termoneutro, em que a energia do alimento não é desviada para compensar os extremos térmicos para eliminar ou manter o seu calor.

Para que a criação avícola seja economicamente viável, é necessário que as aves sejam mantidas dentro de uma faixa de temperatura com poucas variações. Para frangos de corte, essa faixa denomina-se zona de termoneutralidade e está situada entre 18 e $26^{\circ} \mathrm{C}$, de acordo com CAMPOS (1995) e BAETA e SOUZA (1997).

Normalmente, as rações formuladas para aves em ambiente termoneutro buscam atender às exigências em proteína bruta (PB), energia metabolizável (EM), vitaminas e minerais, contudo, podem conter excessos de aminoácidos essenciais. A digestão e o metabolismo desses aminoácidos geram incremento calórico desnecessário, além de gasto de energia para promover a excreção dos mesmos, como ácido úrico.

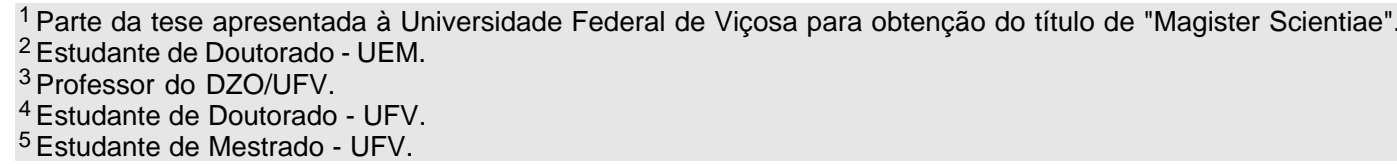


A suplementação de aminoácidos sintéticos nas rações comerciais, como forma de reduzir o teor de $\mathrm{PB}$ e, conseqüentemente, das fontes protéicas, tem merecido especial atenção dos pesquisadores (BAKER e SPEER, 1983). Isso tem proporcionado facilidades no ajuste das formulações dessas rações, possibilitando, assim, a obtenção dos níveis mínimos exigidos de aminoácidos essenciais. Além disso, PARSONS e BAKER (1994) relataram que, em situações práticas, Met + Cis, lisina, treonina, triptofano e arginina são os aminoácidos de maior importância para a produção de aves e suínos. Dentre esses, a lisina é considerada o aminoácido referência no conceito da proteína ideal, por ser o primeiro aminoácido limitante na maioria das rações para suínos e o segundo limitante, depois da metionina + cistina, para as rações de aves; além do fato de a lisina ter função importante na formação de proteína no organismo e de atuar no metabolismo dos lipídeos como percursor da carnitina.

Com base nestas informações, conduziu-se este trabalho com o objetivo de estabelecer planos de nutrição, para frangos de corte no período de 1 a 49 dias de idade.

\section{Material e Métodos}

Este experimento foi conduzido no Laboratório de Bioclimatologia Animal, do Departamento de Zootecnia, da Universidade Federal de Viçosa.

Foram utilizados 240 pintos de um dia de idade, machos, Ross, com peso inicial médio de 43, $0 \pm 0,2 \mathrm{~g}$. $\mathrm{O}$ delineamento experimental utilizado foi o inteiramente casualizado, com quatro tratamentos (quatro planos de nutrição), constituídos por seis repetições de dez aves até aos 41 dias de idade e de sete aves dos 42 aos 49 dias de idade. Na eliminação das três aves por unidade experimental, consideraram-se aquelas com pesos com menor variação em relação à média da repetição.

Os planos de nutrição (PN) corresponderam a quatro diferentes sequiências de lisina total para as fases: inicial (1 a 21 dias de idade), crescimento (22 a 41 dias de idade) e final (42 a 49 dias de idade), estabelecidas com base nas recomendações do NATIONAL RESEARCH COUNCIL - NRC (1994), que correspondem a 1,$10 ; 1,00$; e $0,85 \%$, respectivamente, para as fases inicial, crescimento e final, que ficaram assim constituídos:

PN1 - 1,10\%, 1,00\% e $0,85 \%$ de lisina total;

PN2 - $1,20 \%, 1,10 \%$ e $0,95 \%$ de lisina total;
PN3 - 1,30\%, 1,20\% e 1,05\% de lisina total; e

PN4 - 1,40\%, $1,30 \%$ e $1,15 \%$ de lisina total.

Na formulação das rações experimentais, os níveis de proteína bruta (PB), energia metabolizável (EM), minerais e vitaminas seguiram as recomendações nutricionais de ROSTAGNO et al. (1996), para as fases inicial, crescimento e final (Tabela 1). As rações foram suplementadas com L-lisina. $\mathrm{HCl} 78,4 \%$, obtendo-se, assim, os níveis de lisina total para cada fase.

Os aminoácidos DL-metionina, L-treonina, L-isoleucina, L-arginina e L-triptofano foram utilizados em quantidade necessárias para atender ou exceder o padrão de proteína ideal, segundo a relação de BAKER e HAN (1994) para aminoácidos digestíveis, em que a lisina equivale a $100 \%$; metionina, 36 e 37\%; treonina, 67 e 70\%; isoleucina, 67\%; arginina, $105 \%$; e triptofano, 16 e $17 \%$, respectivamente, para 0 a 21 e 22 a 49 dias de idade. A composição em aminoácidos digestíveis das rações foi calculada utilizando os valores dos coeficientes de digestibilidade dos aminoácidos dos ingredientes contidos nas tabelas RHODIMET... (1993).

As aves foram alojadas em quatro baterias metálicas, contendo 12 compartimentos de $0,72 \mathrm{~m}^{2}$ providos de bebedouros e comedouros tipo calha, mantidos nas salas climatizadas.

As temperaturas e umidades relativas das salas foram registradas, duas vezes ao dia $(8 \mathrm{e} 18 \mathrm{~h}$ ), por meio de termômetros de bulbo seco e úmido e de globo negro, mantidos no centro da sala. Posteriormente, estas leituras foram convertidas em um único valor, denominado Índice de Temperatura de Globo e Umidade (ITGU), proposto por BUFFINGTON et al. (1977), que é a combinação dos efeitos de umidade, velocidade do ar, temperatura de bulbo seco e da radiação.

O programa de luz adotado durante todo o período experimental foi o contínuo ( 24 horas de luz artificial), fazendo-se uso de duas lâmpadas fluorescentes de $75 \mathrm{~W}$, por sala.

A ração e a água foram fornecidas à vontade durante todo o período experimental. Para avaliar os planos de nutrição, as aves foram pesadas com $41 \mathrm{e}$ com 49 dias de idade, para posterior determinação do ganho de peso. Da mesma forma, o consumo de ração foi calculado considerando-se a ração fornecida, os desperdícios e as sobras das rações nos comedouros. Posteriormente, calculou-se a conversão alimentar.

No final do período experimental, as aves foram pesadas após jejum alimentar de seis horas. Quatro aves em cada unidade experimental, com peso $10 \%$ acima ou abaixo da média da unidade, foram abatidas. 
Rev. bras. zootec.

427

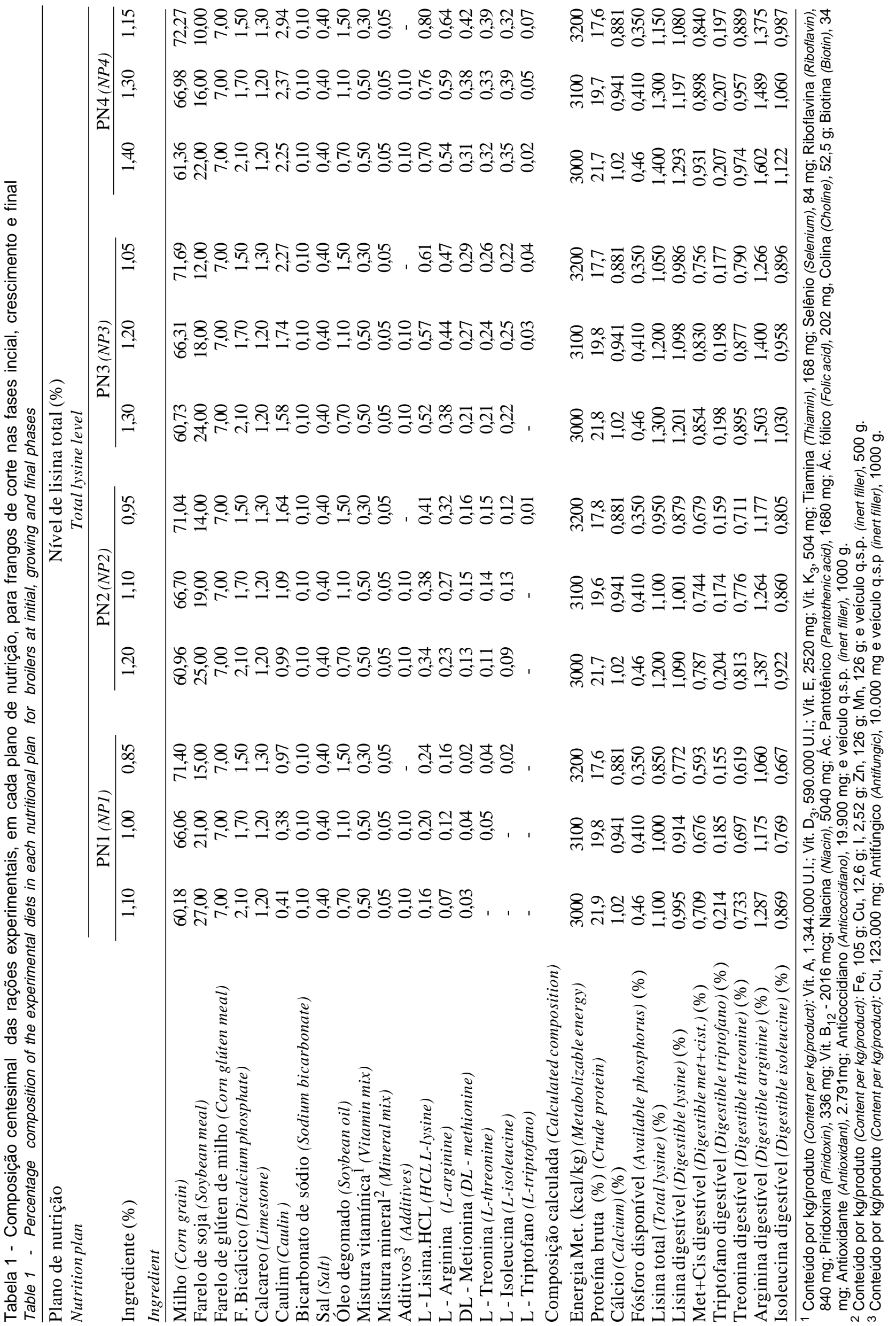


Foram avaliados os pesos, absoluto (g) e relativo (\%), das carcaças inteiras (com pés e cabeça), dos cortes nobres (peito, peito sem osso, coxa e sobrecoxa) e do peso de órgãos (coração, fígado e moela).

As análises estatísticas dos níveis estudados foram feitas por intermédio do programa SAEG (Sistema de Análises Estatísticas e Genéticas), desenvolvido na UNIVERSIDADE FEDERAL DE VIÇOSA - UFV (1997). Na comparação das médias, utilizou-se o teste de "Student Newman Keuls", a 5\% de probabilidade.

\section{Resultados e Discussão}

As médias da temperatura e umidade relativa do ar, assim como o Índice de Temperatura de Globo e Umidade (ITGU), registradas durante todo o período experimental no interior das câmaras climáticas, constam da Tabela 2.

Os resultados de desempenho de frangos de corte de 1 a 41 dias e de 1 a 49 dias de idade são apresentados na Tabela 3 .

Não se observou efeito $(\mathrm{P}>0,05)$ dos planos de nutrição (PN) sobre o ganho de peso (GP) das aves em ambos os períodos, apesar de o GP ter sido 5,4\% maior para as aves submetidas ao plano de nutrição (PN) 4 em relação ao PN1, na fase de 1 a 41 dias. Estes resultados diferem daqueles obtidos por HOLSHEIMER e VEERKAMP (1992), que, trabalhando com frangos de corte, de 1 a 42 dias de idade, fornecendo uma única ração para a fase inicial e crescimento, constataram melhor ganho de peso das aves com o nível de $1,36 \%$ de lisina total, e daqueles de BARBOZA (1998), que observou melhores GP

Tabela 2 - Condições ambientais observadas durante a fase experimental ${ }^{1}$

Table 2 - Environment conditions observed during the experimental period ${ }^{1}$

\begin{tabular}{lccc}
\hline $\begin{array}{l}\text { Idade (dias) } \\
\text { Age (days) }\end{array}$ & $\begin{array}{c}\text { Temperatura } \\
\text { do } \operatorname{ar}\left({ }^{\circ} \mathrm{C}\right) \\
\text { Air temperature }\end{array}$ & $\begin{array}{c}\text { Umidade } \\
\text { relativa }(\%)\end{array}$ & $\begin{array}{c}\text { ITGU } \\
\text { Relative humity }\end{array}$ \\
\hline 1 & $32,1 \pm 0,25$ & $54,5 \pm 1,00$ & $81,6 \pm 0,59$ \\
2 & $31,5 \pm 0,57$ & $50,8 \pm 2,21$ & $80,8 \pm 0,63$ \\
$3-4$ & $31,0 \pm 0,00$ & $49,7 \pm 3,06$ & $79,8 \pm 0,22$ \\
$5-8$ & $28,8 \pm 0,41$ & $52,5 \pm 2,47$ & $77,1 \pm 0,51$ \\
$9-11$ & $27,9 \pm 0,56$ & $57,4 \pm 2,20$ & $76,3 \pm 0,59$ \\
$12-16$ & $26,4 \pm 0,78$ & $62,6 \pm 3,01$ & $75,2 \pm 0,73$ \\
$17-21$ & $24,3 \pm 0,68$ & $65,9 \pm 2,99$ & $72,9 \pm 1,14$ \\
$22-41$ & $21,6 \pm 0,90$ & $66,3 \pm 2,98$ & $69,7 \pm 1,04$ \\
$42-49$ & $21,0 \pm 0,56$ & $68,3 \pm 3,53$ & $68,8 \pm 0,50$ \\
\hline
\end{tabular}

1 Valores médios (Average values). com os níveis de 1,19; 0,98; e $0,75 \%$ de lisina total, para frangos de corte, de 1 a 21, 22 a 40 e 42 a 49 dias de idade, respectivamente, criados em ambiente com temperatura média entre 22 e $24^{\circ} \mathrm{C}$.

O consumo de ração (CR) e a conversão alimentar (CA) também não foram influenciados $(\mathrm{P}>0,05)$ pelos planos de nutrição, nas duas fases avaliadas. $\mathrm{O}$ fato de as aves terem sido mantidas em ambiente de conforto, recebendo rações isoenergéticas e de similar qualidade de proteína, mantida pela suplementação de até seis aminoácidos, considerando a relação aminoacídica no conceito de proteína ideal, pode ter contribuído para que o $\mathrm{CR}$ e a $\mathrm{CA}$ não variassem entre os tratamentos.

De acordo com resultados de CONHALATO (1998), o consumo de ração e a conversão alimentar de frangos de corte, na fase inicial, não foram influenciados significativamente pelos níveis de lisina $(1,05$ a $1,35 \%)$ da ração, quando a relação aminoacídica foi mantida.

A variação não-significativa de 4,9\% no CR das aves entre o PN4 e o PN1 justifica aquela variação de $5,4 \%$ ocorrida no GP, entre estes tratamentos no período de 1 a 41 dias.

Os resultados de CA, obtidos com o plano de nutrição 1 , com exceção do nível de lisina utilizado na fase inicial $(1,10 \%)$, estão coerentes com aqueles verificados por BARBOZA (1998), que observaram melhores resultados de CA dos frangos de corte, com os níveis de 1,18;0,98; e 0,87\% de lisina total, para as fases inicial, crescimento e final, respectivamente.

Com os dados de desempenho observados, pode-se inferir que o plano de nutrição 1 , correspondente aos níveis de lisina total de 1,$10 ; 1,00$; e $0,85 \%$, pareceu adequado para frangos de corte nas fases inicial, crescimento e final, respectivamente. Estes valores de lisina foram similares àqueles recomendados pelo NRC (1994), para as diferentes fases, e inferiores aqueles preconizados por ROSTAGNO et al. (1996), que correspondem a 1,$16 ; 1,05$; e $0,90 \%$ de lisina total, para as respectivas fases inicial, crescimento e final, e COSTA et al. (1999a, b), que estimaram em 1,27 e $1,16 \%$ de lisina total para as fases inicial e de crescimento, respectivamente. A variação de resultados observada entre os diferentes trabalhos pode estar relacionada, entre outros fatores, com a linhagem das aves, condição ambiental e composição das rações experimentais utilizadas.

Os pesos absolutos, os rendimentos de carcaça e dos cortes nobres (coxa, sobrecoxa, peito e peito sem osso) das aves aos 49 dias de idade, nos diferentes 
Rev. bras. zootec.

Tabela 3 - Ganho de peso médio, consumo de ração e conversão alimentar de frangos de corte no período de 1 a 41 dias e 1 a 49 dias de idade, em ambiente de conforto térmico

Table 3 - Average weight gain, feed intake and feed:gain ratio of broilers from 1 to $41 d$-old and from 1 to $49 \mathrm{~d}$-old, under thermal comfort environments

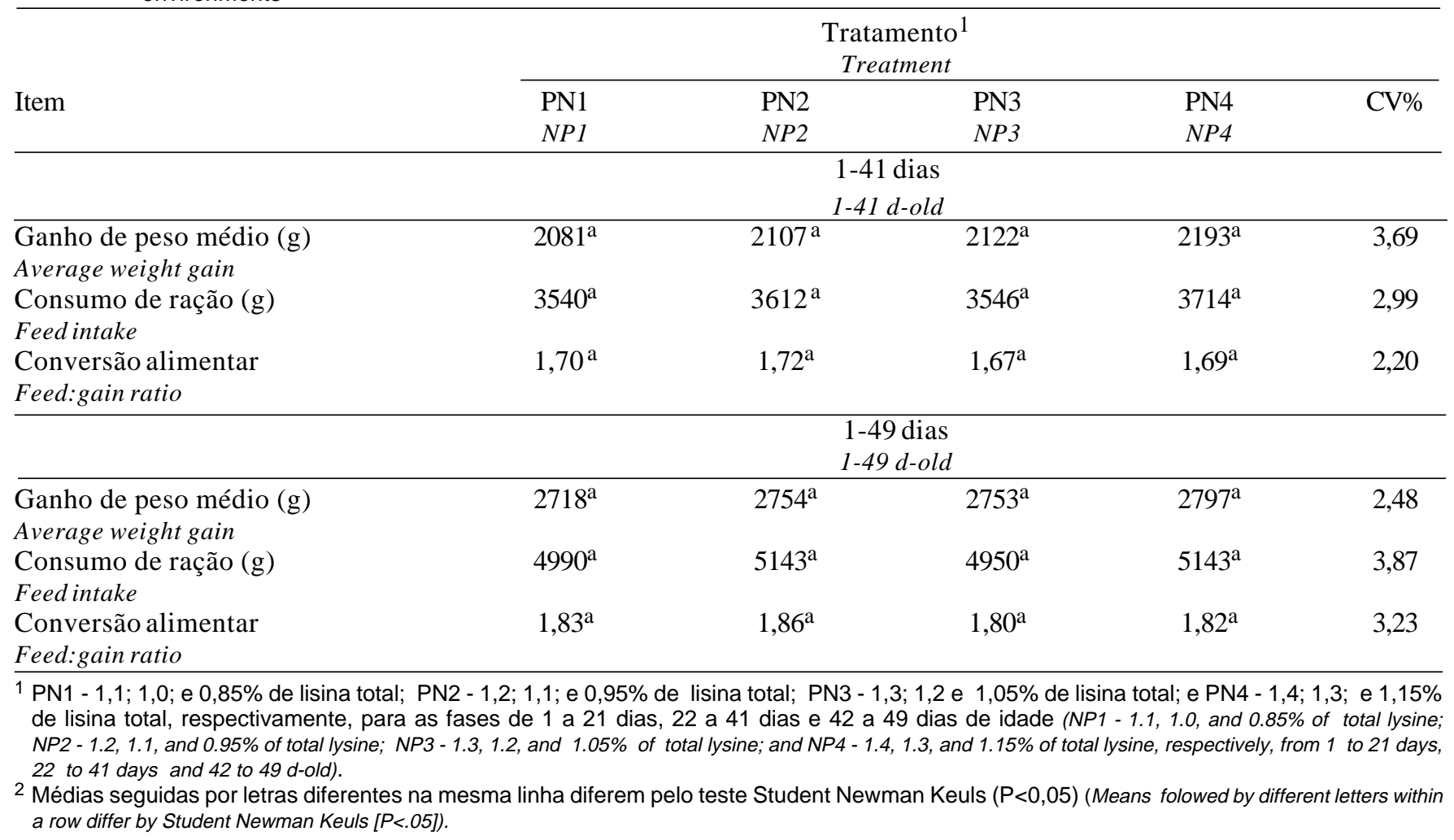

planos nutricionais, são apresentados na Tabela 4.

Não se observou efeito $(\mathrm{P}>0,05)$ dos tratamentos sobre o peso das aves após jejum e os pesos absoluto e relativo de coxa e sobrecoxa. Estes resultados estão coerentes com os obtidos por JUNQUEIRA et al. (1998), que também não observaram efeito dos níveis de lisina sobre os pesos da coxa e sobrecoxa.

Constataram-se maiores $(\mathrm{P}<0,05)$ pesos, absoluto e relativo, de peito e peito sem osso das aves que receberam o plano de nutrição 3 em relação àquelas que receberam o plano de nutrição 1 . As aves que receberam os planos 2 e 4 apresentaram valores intermediários de pesos, absoluto e relativo, de peito, que não diferiram entre si, e nem dos demais tratamentos. Resultados discordantes foram obtidos por BARBOSA et al. (1998), que não observaram efeito dos níveis de lisina total sobre o peso e rendimento de peito. Com relação ao peito sem osso, constatou-se que as aves do $\mathrm{PN} 1$ apresentaram menores $(\mathrm{P}<0,05)$ pesos, absoluto e relativo, em relação aos demais tratamentos, que não diferiram $(\mathrm{P}>0,05)$ entre si.

Estes resultados evidenciaram que, embora os planos de nutrição não tenham influenciado o desempenho das aves (GP, CR e CA), a composição do ganho variou com os tratamentos, com as aves recebendo o PN1, apresentando piores resultados de pesos, absoluto e relativo, de peito e peito sem osso. Este resultado está coerente com o relato de SIBBALD e WOLYNETS (1986) de que o requerimento de aminoácidos essenciais para ótima produção de carne de peito é maior que para crescimento e o de KIDD et al. (1997) de que a ótima deposição de tecido de peito em frangos pode ser obtida com níveis de lisina acima do recomendado pelo NRC (1994).

Considerando que a carne de peito é o componente da carcaça com maior valor de mercado e esta aumenta linearmente como porcentagem do peso corporal e proteína do corpo (Acar et al., 1993, citados por MACK e PACK, 2000), qualquer limitação no fornecimento de aminoácidos essenciais na ração pode comprometer a deposição de carne de peito e, conseqüentemente, a lucratividade da exploração. De acordo com KIDD et al. (1997), as companhias avícolas americanas têm buscado, por meio da seleção genética, o aumento da produção de 
Tabela 4 - Peso absoluto e rendimento da carcaça e cortes nobres de frangos de corte, submetidos a diferentes níveis de lisina no período de 1 a 49 dias de idade, em ambiente de conforto térmico

Table 4 - Absolute weight and carcass and edible parts yield of broilers, submitted to different lysine levels on the period from 1 to $49 \mathrm{~d}$ old under thermal comfort environments

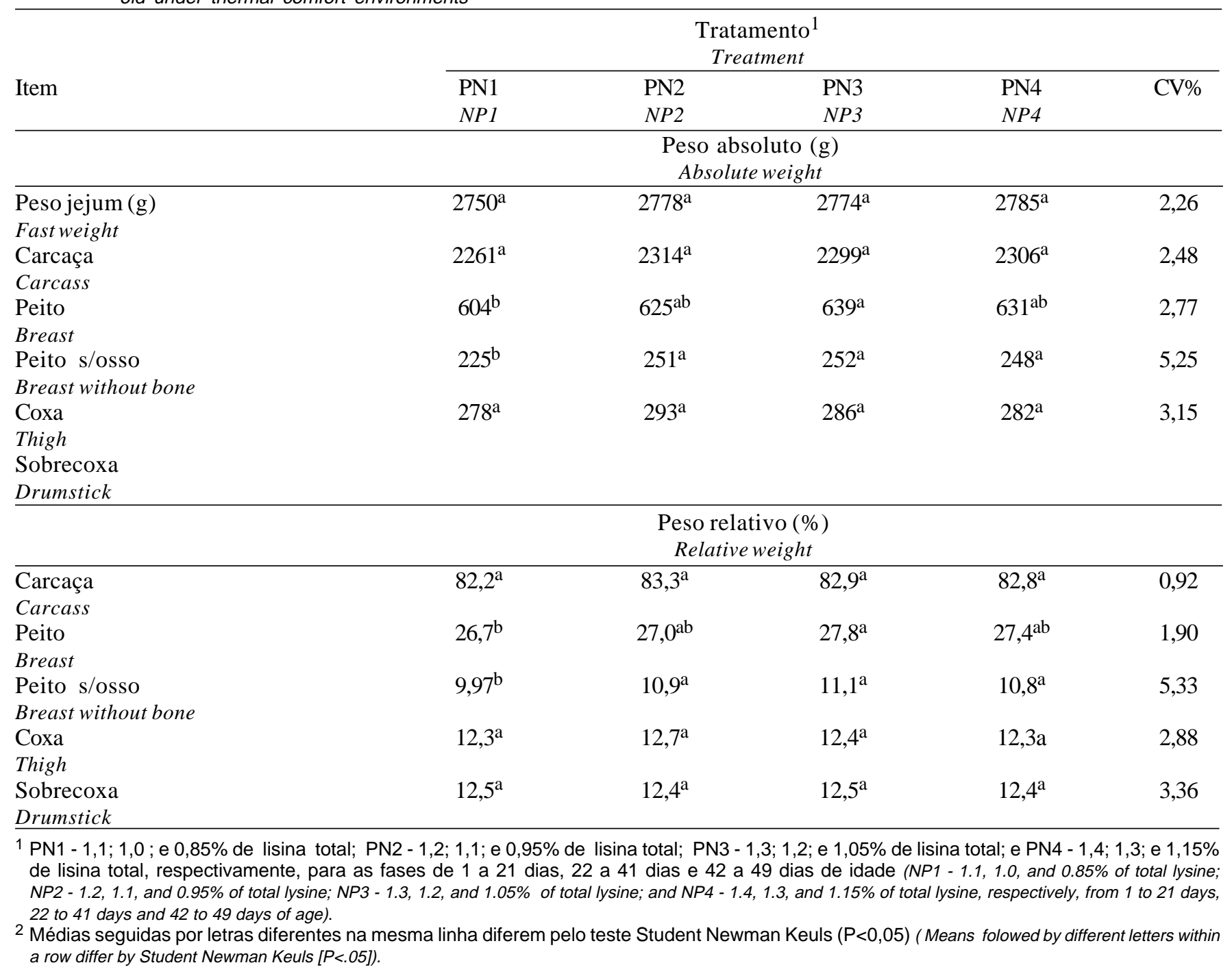

carne de peito em frangos de corte comerciais para atender a demanda daquele mercado.

Os pesos, absoluto e relativo, dos órgãos comestíveis (coração, fígado e moela) dos frangos de corte machos, aos 49 dias de idade, submetidos aos diferentes planos de nutrição são apresentados na Tabela 5 .

Observou-se que os pesos, absoluto e relativo, do coração e da moela não foram influenciados pelos planos nutricionais. Estes resultados estão de acordo com aqueles obtidos por ARAÚJO et al. (1999), que também não encontraram efeito dos níveis de lisina sobre o peso do coração e moela de frangos de corte na fase final de criação.
Por outro lado, os planos de nutrição influenciaram $(\mathrm{P}<0,05)$ os pesos absoluto e relativo do fígado, com as aves do PN1, apresentando maiores pesos, absoluto e relativo, de fígado em comparação àquelas do PN3. Já as aves submetidas aos PN2 e PN4 apresentaram valores similares $(P>0,05)$ de pesos, absoluto e relativo, de fígado, que também não variaram $(P>0,05)$ em relação aos demais tratamentos. Estes resultados estão em desacordo com aqueles obtidos por BARBOSA et al.(1998), que, trabalhando com diferentes níveis de lisina e treonina, não observaram efeito dos tratamentos sobre o peso do fígado das aves. 
Rev. bras. zootec.

Tabela 5 - Peso absoluto e relativo dos órgãos comestíveis de frangos de corte submetidos a diferentes níveis de lisina no período de 1-49 dias de idade, em ambiente de conforto térmico

Table 5 - Absolute and relative weight of the organs of broilers submitted to different lysine levels from 1 to 49 d-old of under thermal comfort environments

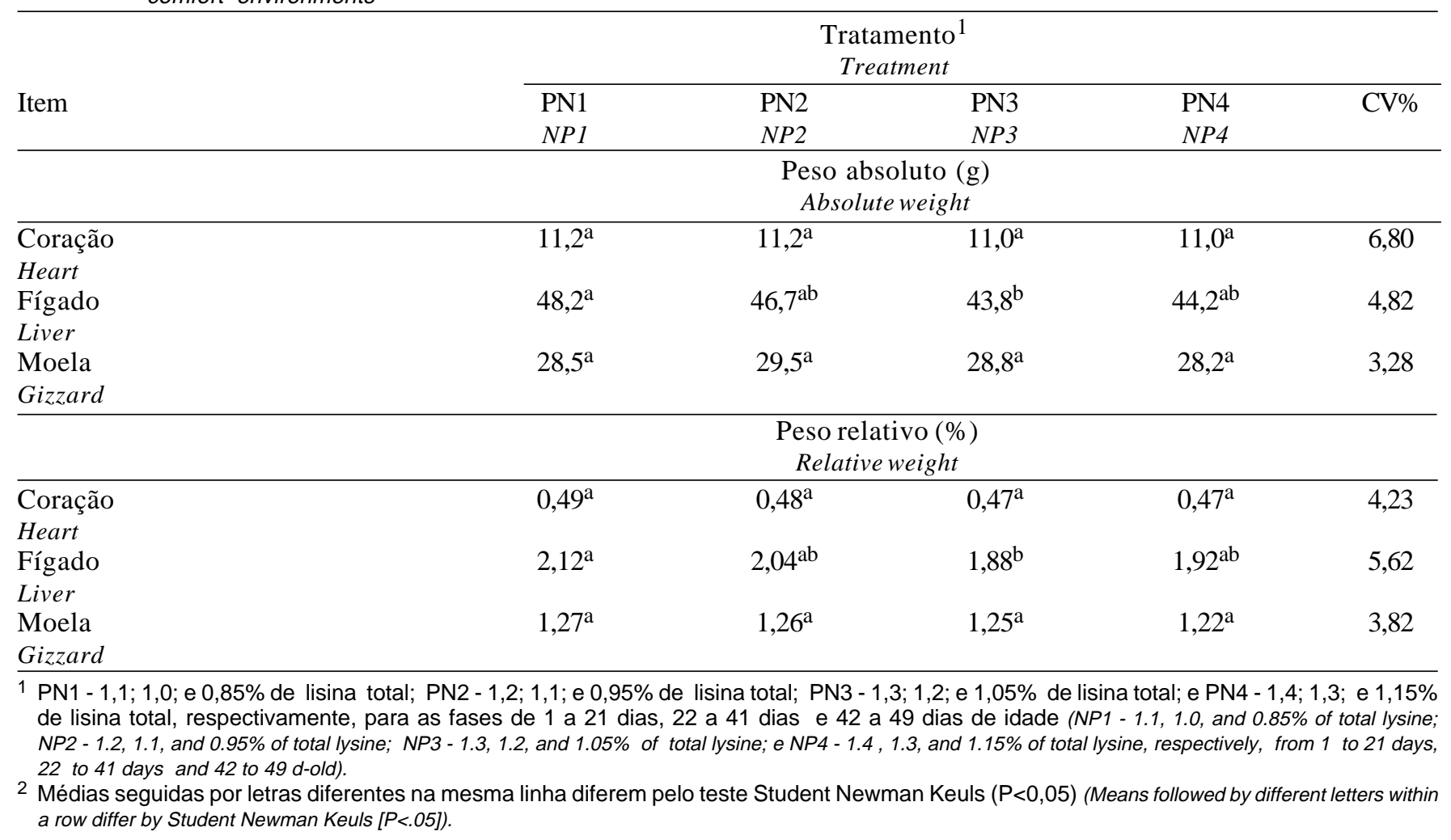

\section{Conclusões}

Concluiu-se, com base nos resultados de desempenho, que qualquer dos planos avaliados atende às exigências de frangos de corte nas diferentes fases estudadas, quando mantidos em ambiente de conforto térmico.

Se considerados os dados de rendimentos de cortes nobres, os planos 2, 3 e 4 proporcionaram os melhores resultados.

\section{Referências Bibliográficas}

ARAÚJO, L.F., JUNQUEIRA, O.M., ARAÚJO, C.S.S. et al. Diferentes níveis de lisina para duas linhagens defrangos de corte nafase final de criação. In: CONFERÊNCIA APINCO 1999DE CIÊNCIAS E TECNOLOGIAS AVÍCOLAS, p.43, 1999.

BAETA, F.C., SOUZA, C.F. 1997. Ambiência em edificações. Viçosa, MG: UFV. 246p.

BAKER, D.H., HAN, Y. 1994. Ideal amino acid profile for chicks during the first three weeks posthatching. Poult. Sci., 73:1441-1447.

BAKER, D.H., SPEER, V.C. 1983. Protein - amino nutrition of non-ruminant animals with emphasis on the pigs: past, present, future. J. Anim. Sci., 57:284-299.

BARBOSA, M.J.B, JUNQUEIRA, O.M., ARAÚJO L.F. et al.
Avaliação do desempenho de frangos de corte submetidos a diferentes níveis de treonina e lisina na fase final de criação. In: CONFERÊNCIA APINCO 1998 DE CIÊNCIAS E TECNOLOGIAS AVÍCOLAS, 1998. p.30.

BARBOZA, W.A. Exigência nutricional de lisina para duas marcas comerciais de frango de corte. Viçosa: UFV, 1998. 115p. Tese (Doutorado em Zootecnia) - Universidade Federal de Viçosa, 1998.

BUFFINGTON, D.E., COLAZZO-AROCHO, A.,CANTON, G.H. et al. 1977. Black globe-umidity confort index for dairy cows. St. Joseph, Michigan, Amer. Soc. Agric. Eng. 19p.

CAMPOS, E.J. Programa de alimentação e nutrição para as aves de acordo com o clima. Reprodutoras. In: SIMPÓSIO INTERNACIONAL DE AMBIÊNCIA E INSTALAÇÃO NA AVICULTURA INDUSTRIAL, 1995, Campinas, SP. Anais... Campinas, SP: Editora FACTA, 1995. p.251-257.

CONHALATO, G.S. Exigência de lisina digestível parafrangos de corte machos. Viçosa: UFV, 1998. 68p. Dissertação (Mestrado em Zootecnia) - Universidade Federal de Viçosa, 1988.

COSTA, F.G.P., ROSTAGNO, H.S., ALBINO, L.F.T. et al. Níveis dietéticos de lisina para frangos de corte, no período de 1 a 21 dias de idade. In: CONFERÊNCIA APINCO 1999 DE CIÊNCIAS E TECNOLOGIAS AVÍCOLAS, 1999a. p.17.

COSTA, F.G.P., ROSTAGNO, H.S., ALBINO, L.F.T. et al. Níveis dietéticos de lisina para frangos de corte, no período de 22 a 40 dias de idade. In: Conferência APINCO 1999 de CIÊNCIAS E TECNOLOGIAS AVÍCOLAS, 1999b. p.18.

HOLSHEIMER, J.P., VEERKAMP, C.H. 1992. Effect of dietary, protein, and lysine content on performance and yields of two 
strains of male broiler chicks. Poult. Sci., 71:872-879.

JUNQUEIRA, O.M., ARAÚJO L.F., SILVA, C.S. et al. Níveis de lisina e metionina sobre o desempenho e rendimento de carcaça de frangos de corte na fase final de criação. In: CONFERÊNCIA APINCO 1998 DE CIÊNCIAS E TECNOLOGIAS AVÍCOLAS, 1998. p.19.

KIDD, M.T., KERR, B.J., ANTHONY, N.B. 1997. Dietary interactions between lysine and treonine in broilers. Poult. Sci., 76:608-614.

KINO, K., OKUMURA, J. 1986. The effect of single essential amino acid deprivation on chick growth and nitrogen and energy balances at ad libitum - and equalized-food intakes. Poult. Sci., 65:1728-1735.

MACK, S., PACK, M. Desenvolvimento de carcaça de frango: influência dos aminoácidos da dieta. In: CONFERÊNCIA APINCO 2000 DE CIÊNCIAS E TECNOLOGIAS AVÍCOLAS, 2000. p.145-160.

NATIONAL RESEARCH COUNCIL - NRC. 1994. Nutrient requirement of poultry. 9.ed. Washington, D.C.: National Academy Press. 155p.

PARSONS, C.M., BAKER, D.H. The concept and use of ideal proteíns in the feeding of nonruminants. In: SIMPÓSIO INTERNACIONAL DE PRODUÇÃO DE NÃO RUMINANTES, 1994, Maringá, PR. Anais... Maringá: SBZ, 1994. p.119-128.
RHODIMET feed formulation guide. 1993. 6.ed. France: Rhône- Poulenc Animal Nutrition. 39p.

ROSTAGNO, H.S., BARBARINO JR., P., BARBOZA, W.A. Exigências nutricionais das aves determinadas no Brasil. In: SIMPÓSIO INTERNACIONAL SOBRE EXIGÊNCIAS NUTRICIONAIS DE AVES E SUÍNOS, 1996, Viçosa. Anais... Viçosa, 1996. p.361.

SIBBALD, I.R., WOLYNETZ, S. 1986. Effects of dietary lysine and feed intake on energy utilization and tissue synthesis by broiler chicks. Poult. Sci., 65:98-105.

UNIVERSIDADE FEDERAL DE VIÇOSA - UFV. 1997. SAEG - Sistemas de análises estáticas e genéticas. Versão 7.1. Viçosa, MG. 150p. (Manual do usuário).

Recebido em: 24/03/00

Aceito em: 09/11/00 